\title{
Comparison of the erossbred progeny of belgian landrace and pietrain boars
}

\author{
P. SELLIER \\ Station de Génétique animale, I. N.R. A., C.N.R.Z., \\ 78350 Jouy en Josas
}

Both Belgian Landrace and Pietrain boars were randomly used by A.I. on French Landrace $\times$ Large White sows of commercial farms. Females and castrates from resultant litters were sent to an experimental station where they were fed ad libitum (test starting at $30 \mathrm{~kg}$ ) and slaughtered at about roo kg. Data were recorded on 164 pigs from $2 \mathrm{I}$ litters sired by 12 Belgian Landrace boars (XLB) and on $5_{5} 2$ pigs from 22 litters sired by 5 Pietrain boars (XPP). Daily feed consumption was Io p. Ioo $(\mathrm{P}<0.00 \mathrm{I})$ higher in XLB pigs which excel XPP pigs in average daily gain on test; however an interaction sex $\times$ breeding group $(\mathrm{P}<0$.or) was evidenced for the latter trait : the advantage of XLB was larger in barrows ( I I I g) than in gilts $(57 \mathrm{~g})$. The same interaction tends to cxist for food conversion ( $\left.P^{\prime}<0.15\right): 3.16 \mathrm{vs} 3.37$ in barrows, $3.23 \mathrm{vs} 3.27$ in gilts for XLB and XPP groups, respectively. No significant difference between breeding groups was found in (Iressing out percentage, average backfat thickness, weight of backfat and weight of ham; however XPP pigs had a shorter carcass $\left(\mathrm{I}^{\prime}<0.00 \mathrm{I}\right)$, a higher weight of loin $(\mathrm{P}<0.00 \mathrm{I})$ and a lower weight of leaf fat $(\mathrm{P}<0.05)$. A slight superiority of XLB pigs as compared to XPP pigs was found with respect to meat quality, assessed 24 hours post mortem. The 3-way cross with Belgian Landrace boars showed a mean advantage of about Ir.5 F per pig on the 3-way cross with Pietrain boars in overall economic merit but due to the interaction sex $\times$ breeding group for fattening cost, the difference was larger in barrows ( $7.5 F)$ than in gilts $(5.5 \mathrm{li})$.

\section{Study of the malignant hyperthermia syndrome in pietrain breed : first results}

\author{
G. MONIN, L. OLLIVIER*, P. SELLIER* \\ Station de Recherches sur la Viande, I. N. R. A., \\ Theix, Saint Genès Champanelle, 63110 Beaumont \\ * Station de Génétique animale, I. N.R.A., C.N.R.Z., \\ 78350 Jouy en Josas
}

A sample of 138 Pietrain females and castrates was subjected to a 5-minute anaesthesia with halothane, at an age of about 8 o days. Thirty-nine of them, denoted $(+)$, exhibited the malignant hyperthermia syndrome after an average $2 \mathrm{I} / 2$ minute anaesthesia while the others 